\title{
PATIENTS WITH TUBEROUS SCLEROSIS HAVE FIBROBLASTS WITH NORMAL LIMITS FOR GROWTH CHARACTERISTICS AND SENSITIVITIES TO DNA ALKYLATING AGENTS
}

\author{
Kousaku OHNo and Kenzo TAKESHITA \\ Division of Child Neurology, Institute of Neurological Sciences, \\ Tottori University School of Medicine, Yonago 683, Japan
}

\begin{abstract}
Summary Tuberous sclerosis (TS) is an autosomal dominant neurocutaneous syndrome characterized by hamartomatous growth in multisystems. To determine the gene expression in cultured fibroblasts, we studied several in vitro properties of skin fibroblasts. Measurements of the attachment ratio, the colony-forming efficiency, the population doubling time, and the saturation density in $10 \%$ fetal bovine serum show that fibroblasts from five TS patients proliferate in the same manner as do the age-matched controls. We also measured the survival of TS fibroblasts after treatment with a variety of chemical agents. TS fibroblasts are equal to controls in their sensitivity to four types of alkylating agents including $N$-methyl- $N^{\prime}$-nitro- $N$-nitrosoguanidine to which TS fibroblasts have been reported to be hypersensitive. These results suggest that the in vitro properties of TS fibroblasts do not resemble cells from patients with several autosomal recessive disorders predisposing to neoplasms and displaying hypersensitivity to DNA damages.
\end{abstract}

\section{INTRODUCTION}

Some hereditary deficiencies predispose the affected individuals to benign or malignant neoplasms (for review, see Mulvihill, 1977). In the case of several disorders, the in vitro behavior of cells from such patients is abnormal with respect to growth parameters and sensitivity to a variety of DNA damaging agents. Decreased growth was evident in fibroblast strains from patients with ataxia telangiectasia (AT) (Elmore and Swift, 1976a), Fanconi anemia (Elmore and Swift, 1976b, Weksberg et al., 1979) and von Recklinghausen disease (Zelkowitz, 1981), and has been suggested in case of cells from patients with Cockayne syndrome and Bloom syndrome (Weksberg et al., 1979). These disorders, except for von Recklinghausen disease, have all autosomal recessive traits and their cells display a hypersensitivity to lethal 
effects of ionizing radiation, ultraviolet (UV) light or DNA cross-linking agents. Enhanced growth, i.e. ability to proliferate under suboptimal nutrient conditions, has been recognized in cases of hereditary adenomatosis of colon and rectum (ACR) (Pfeffer et al., 1976) and retinoblastoma (Kossakowska et al., 1982), which are autosomal dominant disorders. The cells from patients with hereditary retinoblastoma or ACR are possibly hypersensitive to ionizing radiation or DNA alkylating agents (Weichselbaum et al., 1978; Barfknecht and Little, 1982).

Tuberous sclerosis (TS) is regarded as one of these preneoplastic syndromes, in terms of developing hamartomatous neoplasms from many organ systems (for review see Gomez, 1979). Suzuki (1977) and Roos et al. (1977) found no obvious cytogenetic abnormalities in TS, including induced chromosomal aberrations following X-ray or UV irradiations. However Paterson et al. (1982) and Scudiero et al. (1982) reported that the cells from some TS patients were hypersensitive to the lethal effects of ionizing radiation and $N$-methyl- $N^{\prime}$-nitro- $N$-nitrosoguanidine (MNNG), respectively.

As a primary approach to examination of the defect in TS patients, we examined two aspects of the in vitro behavior of cells from TS patients, including the growth properties and the cytotoxicity to a variety of chemicals. The agents we have used include four types of alkylating agents: $\mathrm{MNNG}$, ethylmethane sulfonate (EMS), mitomycin $\mathrm{C}$ (MMC), and 4-nitroquinoline- $N$-oxide (4NQO). Among these chemicals, cells from AT patients (Scudiero, 1980) and from patients with hereditary neurologic disorders (Scudiero et al., 1981) are hypersensitive to MNNG, cells from FA patients (Fujiwara et al., 1977) and some AT patients (Hoar and Sargent, 1976) are hypersensitive to $\mathrm{MMC}$, and cells from patients with xeroderma pigmentosum (Takebe et al., 1972) and from patients with Cockayne syndrome (Wada and Chu, 1979) are hypersensitive to 4NQO. We found that TS fibroblasts have normal growth properties with respect to attachment ratio, population doubling time, saturation density, and colony-forming efficiency, and have normal sensitivity to four types of DNA damaging chemicals.

\section{MATERIALS AND METHODS}

Cell culture. Cultures of five TS cell strains were initiated from skin biopsies of the left deltoid area. The strain number is the same as the case number denoted in a previously reported clinical and genetical study (Ohno et al., 1981). All patients were sporadic cases but had typical clinical symptoms. A cell strain from a patient with basal cell nevus syndrome (BCN) was initiated from deltoid skin biopsy. A cell strain (ATkana) derived from a patient with ataxia telangiectasia (AT) was obtained from Prof. M.S. Sasaki, Kyoto University. Control cell strains were obtained from surgical patients and from volunteers with no apparent hereditary disorders: Approximately 30-40 explants from each biopsy were placed into 3-4 plastic Petri dishes of $5.1 \mathrm{~cm}$ (Falcon) and fixed by coverslips that were held in place with silicon 
grease. All strains were grown in $5 \mathrm{ml}$ of Vogt and Dulbecco's modification of Eagle's medium (DEM) with a glucose concentration of $1 \mathrm{~g} /$ liter (GIBCO, Berkeley, Calif.) with $500 \mathrm{IU} / \mathrm{ml}$ penicillin $\mathrm{G}, 100 \mu \mathrm{g} / \mathrm{ml}$ streptmycin sulfate and $10 \%$ fetal bovine serum (FBS) (M.A. Bioproducts, Walkersvilli, Maryland) in $10 \% \mathrm{CO}_{2}(\mathrm{pH}$ 7.4) in humidified air at $37^{\circ} \mathrm{C}$. Primary cultures were fed once a week. Two weeks later, coverslips were turned upside down, affixed again on the same dish apart from the cell sheets on dish, and cultured for one week. Cells on coverslips and surface of dish were dispersed with $0.05 \%$ trypsin in buffered saline containing $0.54 \mathrm{~mm}$ EDTA (Ve buffer) (Kimura et al., 1977). The cells in 3-4 separated dishes were combined and transferred into the same number of $5.1 \mathrm{~cm}$ dishes. When confluence was reached, the cell strains were defined to have accumulated one population doubling level (P.D.L.). Each strain was then passaged with a split ratio of $1: 2$ (add 1 P.D.L.), 1 : 4 (add 2 P.D.L.), or $1: 8$ (add 3 P.D.L.). The culture medium was renewed twice a week until reaching confluence. Cells at P.D.L. 2-3 and P.D.L. 6-8 were stored at $-90^{\circ} \mathrm{C}$. All strains were negative for mycoplasma by fluorescent 33258 Hoechst staining (Chen, 1977).

Growth characteristics. Aliquots of five TS strains, a BCN strains, an AT strain, and control strains (P.D.L. 3-8) frozen at $-90^{\circ} \mathrm{C}$ were thawed and placed in two $5.1 \mathrm{~cm}$ dishes, cultured until reaching confluence, then were split at a ratio of $1: 8$. Two days after, the medium was renewed. At 3 days after subculturing, cells which were considered to proliferate exponentially were used for the experiment. For growth curve analysis, the cells were inoculated at a seeding density of $2 \times 10^{4}$ per $3.3 \mathrm{~cm}$ dish (NUNC, Denmark) in $2 \mathrm{ml}$ of DEM containing $10 \%$ FBS but not antibiotics. Cultures were fed every second day. At various intervals, the cells were removed by trypsinization and counted in hemocytometer. For trypsinization, the plates were washed once with Ve buffer and exposed for approximately five minutes to $0.05 \%$ trypsin in Ve buffer. At least 200 cells were counted from replicating plates. Attachment ratios (ratio of attached cells to inoculated cells) were determined at six hours after the inoculation, population doubling times were determined from the exponential portion of such graphs, and cell numbers on the 15 th day after cell seeding were counted for saturation densities.

Sensitivity to DNA damaging chemicals. To determine the colony-forming efficiency (CFE) and the sensitivity to chemical agents the exponentially growing cells (the same population as used for growth curve analysis) were dispersed and inoculated in $5 \mathrm{ml}$ of antibiotics-free DEM with $10 \%$ FBS at cell densities of 150 and 1,500 cells per $5.1 \mathrm{~cm}$ dish (for an AT strain at cell densities of 300 and 3,000 cells per dish). At six hours after the cell seeding, various concentrations of DNA damaging chemicals were added to the medium. The chemicals used were MNNG (Wako Pure Chemicals, Tokyo), EMS (Sigma Chemicals, St. Louis, Missouri), MMC (Kyowa Hakko Kogyo, Co., Ltd., Tokyo), and 4NQO (Wako Pure Chemicals, Tokyo). EMS and MMC were dissolved in phosphate buffered saline (PBS), $\mathrm{pH} 7.4$, prior to use. MNNG was dissolved in dimethylsulfoxide at a concentration 
of $10 \mathrm{mg} / \mathrm{ml}$ and kept at $-20^{\circ} \mathrm{C}$. 4NQO was dissolved in ethanol at a concentration of $250 \mu \mathrm{g} / \mathrm{ml}$ and kept at $-20^{\circ} \mathrm{C}$. These compounds were diluted into medium immediately before use. After cells were exposed to each chemical for 24 hours, the periods being determined according to Weksberg et al. (1979), cells were rinsed three times with warmed medium without FBS. Then fresh DEM containing $10 \%$ FBS was added to and the cells were cultured. The culture medium was renewed after one week and the cells were cultured for another week, then fixed and stained. Surviving colonies containing more than 50 cells were counted. The CFE, ratio of number of colonies to inoculated cells, was calculated by average colony counts from four dishes unexposed to chemicals. From survival curves, the resulting data were analyzed by linear regression analysis; the value for $D_{0}(1 /$ slope) and for the extrapolation number are the results of this analysis.

\section{RESULTS}

\section{Growth characteristics}

Through primary cultures there were no obvious differences in initial outgrowth of epithelial cells and fibroblasts from explants and in the length of time required to reach initial confluences (P.D.L. 1) between TS strains and controls. However, most of fibroblasts cultured from an angiofibromata from the face of a patient grew very slowly and had large cytoplasms compared with the fibroblasts from unaffected skin of the same patient. These cells from angiofibromata did not proliferate in sufficient amounts to passage serially.

Complete growth curves were obtained from five control fibroblasts, five strains of patients with TS, and two strains from patients with AT and BCN. Figure 1 shows typical growth curves obtained from three different doners. All strains entered the exponentially proliferating phase with short lag periods, and maximum

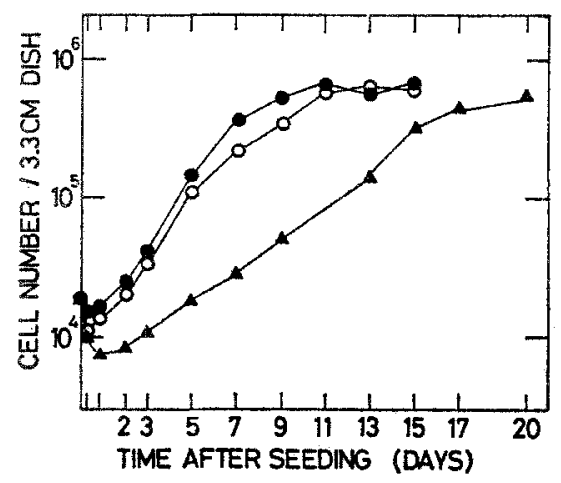

Fig. 1. Growth curves for fibroblast cultures from ( $\bullet$ ) a TS patient (INS-TS27), (ム) an AT patient, and (O) a control (INS-NF2), as described in Materials AND METHODS. 
cell densities were reached the tenth day after inoculation. Thereafter the cell numbers per dish were maintained at fairly constant levels. Fibroblasts from a patient with AT began to multiply with a lag period of about two days, and the growth rate was slower than that seen with other strains (Fig. 1). The growth parameters were obtained, as described in MATERIALS AND METHODS. The saturation density of an AT strain was expressed as the cell number at the 20th day after cell seeding. Table 1 is a summary of the measurements of attachment ratios, population doubling times, and saturation densities for all strains. There were no differences in the population doubling time and the maximum saturation density between control fibroblasts and TS strains. The mean attachement ratio of TS strains was higher than that of control strains, albeit not significantly $(0.05<\mathrm{p}<0.1)$. The growth parameters of a BCN strain were similar to those of TS and control strains. The attachment ratio and the growth rate of a AT strain were low, but the saturation density was within control range.

Measurements of sensitivity to chemicals. To determine whether there were differences in the sensitivity to DNA damaging chemicals between TS strains and controls, we examined the cell survival in terms of colony-forming ability after exposure to MNNG, EMS, MMC, and 4NQO. Suitable doses of these chemicals

Table 1. Summary of data on attachment ratio, growth rate, and saturation density for skin fibroblasts from normal donors and TS patients.

\begin{tabular}{|c|c|c|c|c|c|c|}
\hline Strain & \multicolumn{2}{|c|}{ Status (site of biopsy) } & Age & $\begin{array}{l}\text { Attachement } \\
\text { ratio }\end{array}$ & $\begin{array}{l}\text { Population } \\
\text { doubling } \\
\text { time }\end{array}$ & $\begin{array}{l}\text { Saturation } \\
\text { density per } \\
3.3 \mathrm{~cm} \text { dish }\end{array}$ \\
\hline INS-NF11 & \multicolumn{2}{|c|}{ Cerebral palsy (knee) } & 8 & $65 \%$ & $28 \mathrm{hr}$ & $9.5 \times 10^{5}$ \\
\hline INS-NF19 & \multicolumn{2}{|c|}{ Dislocation of hip (hip) } & 18 & $40 \%$ & $36 \mathrm{hr}$ & $4.2 \times 10^{5}$ \\
\hline INS-NF9 & \multicolumn{2}{|c|}{ Normal (deltoid) } & 24 & $75 \%$ & $33 \mathrm{hr}$ & $7.2 \times 10^{5}$ \\
\hline INS-NF2 & \multicolumn{2}{|l|}{ Normal (deltoid) } & 31 & $55 \%$ & $30 \mathrm{hr}$ & $6.6 \times 10^{5}$ \\
\hline \multirow[t]{3}{*}{ INS-NF7 } & \multirow[t]{3}{*}{ Normal (deltoid) } & & 42 & $75 \%$ & $32 \mathrm{hr}$ & $5.2 \times 10^{5}$ \\
\hline & & mean & 24.6 & $62.0 \%$ & $31.8 \mathrm{hr}$ & $6.5 \times 10^{5}$ \\
\hline & & SE & 5.1 & 5.9 & 1.2 & $8.1 \times 10^{4}$ \\
\hline INS-TS11 & TS (deitoid) & & 14 & $80 \%$ & $30 \mathrm{hr}$ & $7.3 \times 10^{5}$ \\
\hline INS-TS13 & TS (deltoid) & & 16 & $65 \%$ & $34 \mathrm{hr}$ & $7.1 \times 10^{5}$ \\
\hline INS-TS23 & TS (deltoid) & & 27 & $85 \%$ & $28 \mathrm{hr}$ & $4.4 \times 10^{5}$ \\
\hline INS-TS27 & TS (deltoid) & & 31 & $75 \%$ & $28 \mathrm{hr}$ & $6.8 \times 10^{5}$ \\
\hline \multirow[t]{3}{*}{ INS-TS29 } & TS (deltoid) & & 33 & $70 \%$ & $30 \mathrm{hr}$ & $6.4 \times 10^{5}$ \\
\hline & & mean & 24.0 & $75.0 \%$ & $30.0 \mathrm{hr}$ & $6.4 \times 10^{5}$ \\
\hline & & SE & 3.4 & 3.2 & 0.9 .8 & $4.7 \times 10^{4}$ \\
\hline INS-BCN1 & $\mathrm{BCN}$ (deltoid) & & 14 & $63 \%$ & $30 \mathrm{hr}$ & $5.0 \times 10^{5}$ \\
\hline ATkana & $\mathrm{AT}$ & & & $50 \%$ & $52 \mathrm{hr}$ & $5.2 \times 10^{5}$ \\
\hline
\end{tabular}


added to culture medium were determined after several preliminary experiments. A preliminary experiment using density-maximum population of fibroblasts from different aged donors (fetus and ages 4, 24, 31, 42, and 63), all apparently normal, suggested that the sensitivities to MNNG and EMS did not differ with age of donor (data not shown). Other experiment using cells at various states of proliferation from an apparently normal donor (age 4) suggested that the survival patterns after exposure to these chemicals differed somewhat, depending on the state of proliferation of the cells (Fig. 2). Survival curves of exponentially growing cells after exposure to MNNG and MMC gave a smaller shoulder than those of cells at density-maximum or pre-density-maximum phases. The slope of survival curve of exponentially growing cells after exposure to $4 \mathrm{NQO}$ was smaller than that of cells at the density-maximum phase. The survival curves after exposure to EMS was much the same among the cells of various states of proliferation. A smaller experiment using a density-maximum population of two TS strains and age-matched controls showed no obvious difference in survival curves after exposure to MNNG, and EMS (Fig. 3). A more extensive experiment using exponentially growing cells of five TS strains, an AT strain, and a BCN strain, and five control strains was performed as described in MATERIALS AND METHODS. When the logarithm of the surviving fraction (S) is plotted against the dose of chemicals (D) used, the resulting survival curve usually has a small shoulder at low doses followed by an exponential decrease in survival, with increase in the dose. Such curves can be fit by equation.

(a)

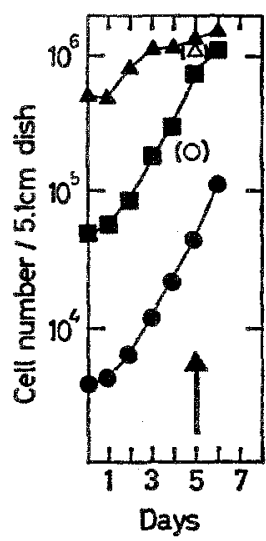

(b)

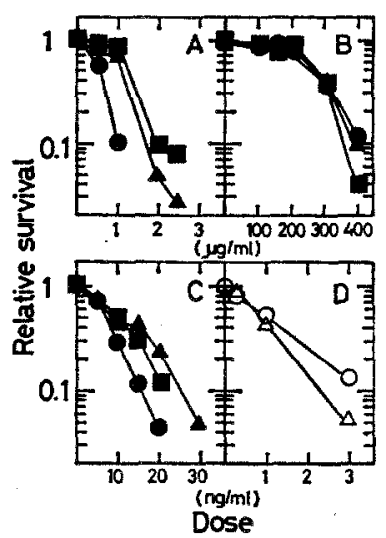

Fig. 2. Survival curves of cells (INS-NF8) at different proliferative states; $(\bullet, 0)$ exponentially proliferating, $(\boldsymbol{\square})$ pre-density-maximum, $(\boldsymbol{\Lambda}, \Delta)$ density-maximum or nonproliferating, after exposure to various concentrations of (A) MNNG, (B) EMS, (C) MMC, and (D) 4NQO (Fig. 2b). Cells seeded at different densities were allowed to proliferate toward confluency. At time point indicated by the arrow in Fig. 2a, each culture was dispersed, seeded at a cell density of 150 cells per $5.1 \mathrm{~cm}$ plate. Six hours later, cells were exposed to each drug for 24 hours and the cultures then washed three times and incubated for 2 weeks. 


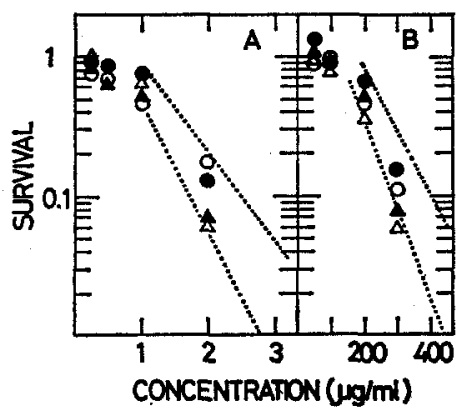

Fig. 3. Survival curves for density-maximum fibroblast cultures from 2 TS patients; ( $\bullet$ INS-TS11 and ( $\Delta$ ) INS-TS23, and 2 control persons; $(O)$ INS-NF9 and $(\triangle)$ INSNF30, after exposure to (A) MNNG and (B) EMS. Cells at a density-maximum state were dipersed, seeded at a cell density of 150 cells per $5.1 \mathrm{~cm}$ dish, and exposed to each drug for 24 hours. (......): survival range of density-maximum cells from different aged controls (fetus, and ages 4, 24, 31, 42, 63).

Table 2. Sensitivity to DNA damaging chemicals. ${ }^{2}$

\begin{tabular}{|c|c|c|c|c|c|c|}
\hline \multirow{2}{*}{ Strain } & & \multirow{2}{*}{$\underset{\%}{\text { CFEd }}$} & \multicolumn{4}{|c|}{$D_{0}^{b}\left(n^{c}\right)$} \\
\hline & & & $\begin{array}{c}\mathrm{MNNG} \\
\mu \mathrm{g} / \mathrm{ml}\end{array}$ & $\begin{array}{l}\mathrm{EMS} \\
\mu \mathrm{g} / \mathrm{ml}\end{array}$ & $\begin{array}{l}\mathrm{MMC} \\
\mathrm{ng} / \mathrm{ml}\end{array}$ & $\begin{array}{l}4 \mathrm{NQO} \\
\mathrm{ng} / \mathrm{ml}\end{array}$ \\
\hline INS-NF11 & & 42.8 & $0.62(2.03)$ & $63.5(11.7)$ & $33.3(1.00)$ & $2.73(1.05)$ \\
\hline INS-NF19 & & 13.8 & $0.52(4.07)$ & $68.5(24.0)$ & $5.1(0.94)$ & $1.09(1.05)$ \\
\hline INS-NF9 & & 28.5 & $0.50(2.71)$ & $62.2(13.4)$ & $4.7(0.95)$ & $1.00(0.99)$ \\
\hline INS-NF2 & & 39.3 & $0.31(22.96)$ & $62.5(23.2)$ & $7.0(1.01)$ & $1.96(1.00)$ \\
\hline \multirow[t]{3}{*}{ INS-NF7 } & & 24.0 & $0.44(4.02)$ & $91.6(2.7)$ & $5.8(0.98)$ & $3.53(1.64)$ \\
\hline & mean & 29.7 & $0.48(7.16)$ & $69.7(15.0)$ & $11.2(0.98)$ & $2.06(1.15)$ \\
\hline & $\mathrm{SE}$ & 4.7 & $0.05(3.55)$ & $5.1(3.5)$ & $5.0(0.01)$ & $0.43(0.11)$ \\
\hline INS-TS11 & & 41.8 & $0.47(1.45)$ & $64.9(11.7)$ & $18.7(1.00)$ & $10.53(1.03)$ \\
\hline INS-TS13 & & 15.8 & $0.64(2.06)$ & $44.3(150.3)$ & $6.7(1.07)$ & $1.43(2.00)$ \\
\hline INS-TS23 & & 29.3 & $0.40(2.99)$ & $90.9(5.4)$ & $7.1(1.02)$ & $1.76(1.00)$ \\
\hline INS-TS27 & & 36.8 & $0.35(5.70)$ & $46.1(271.0)$ & $10.8(1.02)$ & $2.95(1.21)$ \\
\hline \multirow[t]{3}{*}{ INS-TS 29} & & 20.0 & $1.01(1.16)$ & $86.3(7.1)$ & $5.2(1.20)$ & $0.97(2.97)$ \\
\hline & mean & 28.7 & $0.57(2.67)$ & $66.5(89.1)$ & $9.7(1.06)$ & $3.52(1.64)$ \\
\hline & $\mathrm{SE}$ & 4.3 & $0.11(0.73)$ & $8.7(47.5)$ & $2.2(0.03)$ & $1.59(0.34)$ \\
\hline INS-BCN1 & & 44.8 & $0.37(44.60)$ & $60.0(19.5)$ & $6.3(1.16)$ & $1.18(1.04)$ \\
\hline ATkana & & 6.3 & $0.35^{\mathrm{e}}(10.80)$ & $\mathrm{nc}^{\mathrm{f}}$ & $9.8(1.16)$ & $2.06(1.04)$ \\
\hline
\end{tabular}

${ }^{\text {a }}$ This experiment was performed using the same cell population as used in the experiment for the growth curve analysis. b Dose required in the exponential portion of the survival curve to reduce survival $1 / \mathrm{e}(37 \%)$. e Extrapolation number. a CFE: colony-forming efficiency. e The $D_{0}$ for this sample are based on 2 survival values: $\mathbf{f}$ Not calculated. 


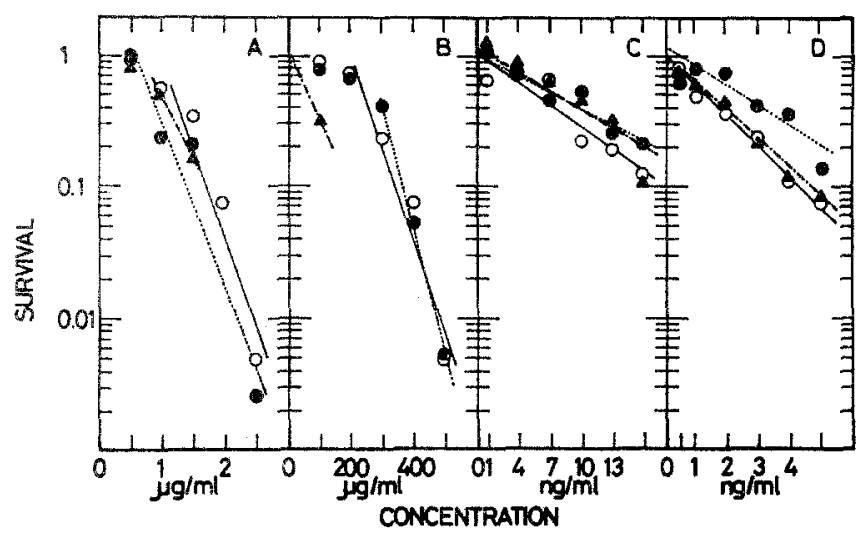

Fig. 4. Survival curves for exponentially proliferating fibroblasts derived from (0) a TS patient (INS-TS27), ( $\Delta$ ) an AT patient, and (O) a control person (INS-NF2), after exposure to (A) MNNG, (B) EMS, (C) MMC, and (D) $4 \mathrm{NQO}$, as described in MATERIALS AND METHODS.

$S=1-\left(1-e^{-D / D_{0}}\right)^{n}$ where $n$ is the extrapolation number of the survival value obtained when the linear portion of the survival curve is extrapolated to zero dose and $D_{0}$ is 1 /slope in the exponential portion of the curve. All of the curves obtained in our study fit the above expression. Figure 4 shows typical survival curves obtained for skin fibroblasts from three different donors after exposure to MNNG, EMS, MMC, and 4NQO. Table 2 summarizes the measurements of CFE, $n$, and $D_{0}$ value. The CFE values of the TS strains and controls were much the same. Although there was a wide variation in the $D_{0}$ values within TS and control groups, there was no significant difference in mean $\mathrm{D}_{0}$ values obtained after exposure to MNNG, EMS, MMC, and 4NQO between TS fibroblasts and control fibroblasts. Although other investigators found that some AT strains are sensitive to MNNG (Scudiero, 1980), MMC (Hoar and Sargent, 1976), and 4NQO (Smith and Paterson, 1980), our data suggest that an AT strain has almost normal sensitivity to MNNG, MMC or 4NQO, as was also noted by Jaspers et al. (1982). With regard to EMS, we did not obtain sufficient values related to survival due to the low CFE. Our data also suggest that the BCN strain has fairly normal sensitivity to these chemicals.

\section{DISCUSSION}

For relevant comparisons of the sensitivity to DNA-damaging agents among strains derived from different donors, it is important to match the growth state of cells, because the degree of cytotoxicity induced by chemical compounds differs, depending on the state of proliferation of the cells (Drewinko and Barlogie, 1982). We found that the survival curves of a cell strain varied at different states of proliferation after exposure to $\mathrm{MNNG}, \mathrm{MMC}$, or $4 \mathrm{NQO}$, whereas there was no varia- 
tion after exposure to EMS (Fig. 2). In C3H10T1/2 mouse embryo fibroblast line, the cytotoxicity induced by MNNG varies through the cell cycle, increasing progressively through $\mathrm{G}_{1}$ and reaching a maximum in the late $S$ phase (McCormick and Bertram, 1982). Therefore, when the exponentially proliferating cells are used, a correspondence of generation times among cell strains compared may be requisite, equalizing the proportion of each cell cycle phase $\left(G_{1}, S, G_{2}\right.$, and $\left.M\right)$ of cell populations during exposure to drugs. The results in the present study show that the growth properties, attachment ratio and colony-forming efficiency of TS strains, a BCN strain, and control strains did not significantly differ from one another, unlike AT fibroblasts which exhibit decreased growth rates and lower colony-forming efficiency (Table 1 and Fig. 1). TS fibroblasts thus probably do not bear resemblance to chromosomal instability syndromes such as AT, Fanconi anemia, or Bloom syndrome, with respect to the growth rate (Elmore and Swift, 1976a, 1976b; Weksberg et al., 1979) and to the colony-forming efficiency (Shiloh et al., 1982).

Our results also show that TS fibroblasts are not different from controls, with respect to their sensitivity to radiomimetic agents (MNNG and EMS), cross-linking agent (MMC), and an UV mimetic agent (4NQO). Paterson et al. (1982) showed that three strains from two TS patients displayed an increased susceptibility to the lethal effects of $\gamma$ radiation whereas a strain from another patient displayed normal sensitivity. The sensitivity of TS strains was intermediate between that of normal controls and that of strains from AT patients. Moshell et al. (1980) and Scudiero et al. (1982) reported that Epstein-Barr virus transformed lymphocyte lines from two TS patients after exposure to ionizing radiation, and fibroblast strains from two TS patients after exposure to MNNG were more lethal than control cells, supporting the rsultes of Paterson et al. (1982).

Our findings were not consistent with their results. Two factors may account for the discrepancy between them. First, as speculated by Jaspers et al. (1982), different experimental protocols and culture conditions may explain discordant results concerning the cytotoxicity of cells after exposure to DNA-damaging agents. In our protocol, cells were exposed to chemicals for 24 hours, starting at six hours after replating, and maintained in DEM throughout the experiments. Scudiero et al. (1982) exposed cells to MNNG in Ham's F12 medium for one hour after replating and incubating for one day, and Paterson et al. (1982) also used Ham's F12 medium. Cells in medium deficient in nicotinamide result in low cellular NAD levels which in turn affect cell survival and DNA repair after exposure to DNAdamaging agents. Jaspers et al. (1982) pointed out Ham's F12 medium contains 100 times less nicotinamide $(0.037 \mathrm{mg} /$ liter $)$ than does DEM ( $4 \mathrm{mg} / \mathrm{liter})$. Second, as suggested by Paterson et al. (1982), clinical heterogeneity in TS may be one reason for the variability in the lethal damage to ionizing radiation or MNNG. It must be mentioned that our patients had typical clinical signs but were all sporadic cases. The lethality after exposure to ionizing radiation or MNNG between fibroblasts from sporadic patients and those from familial cases may also differ. Fibroblasts 
derived from patients with hereditary retinoblastoma are more sensitive to the lethal effects of $\mathrm{X}$ rays than are fibroblasts from patients with sporadic retinoblastoma (Weichselbaum et al., 1978).

Acknowledgments We thank Drs. Genki Kimura, Hisao Takayama, and Takahiko Tanigawa for encouragement and pertinent suggestions, and $\mathrm{M}$. Ohara for reading the manuscript. This work was supported by Grant No. 83-05-19 from the National Center for Nervous, Mental and Muscular Disorders (NCNMMD) of the ministry of Health and Welfare, Japan.

\section{REFERENCES}

Barfknecht, T.R. and Little, J.B. 1982. Abnormal sensitivity of skin fibroblasts from familial polyposis patients to DNA alkylating agents. Cancer Res. 42: 1249-1254.

Chen, T.R. 1977. In situ detection of mycoplasma contamination in cell cultures by fluorescent Hoechst 33258 stain. Exp. Cell Res. 104: 255-262.

Drewinko, B. and Barlogie, B. 1982. The relevance of cell kinetics in determining drug activity in vitro. In Cell Growth, Nicolini, C., ed., Plenum Press, New York, pp. 749-772.

Elmore, E. and Swift, M. 1976a. Growth of cultured cells from patients with ataxia-telangiectasia. J. Cell Physiol. 89: 429-432.

Elmore, E. and Swift, H. 1976b. Growth of cultured cells from patients with Fanconi anemia. J. Cell Physiol. 87: 229-234.

Fujiwara, Y., Tatsumi, M., and Sasaki, M.S. 1977. Cross-link repair in human cells and its possible defect in Fanconi's anemia cells. J. Mol. Biol. 113: 635-649.

Gomez, M.R. (ed.) 1979. Tuberous Sclerosis. Raven Press, New York.

Hoar, D.I. and Sargent, P. 1976. Chemical mutagen hypersensitivity in ataxia telangiectasia. Nature 261: 590-592.

Jaspers, N.G.J., de Wit, J., Regulski, M.R., and Bootsma, D. 1982. Abnormal regulation of DNA replication and increased lethality in ataxia telangiectasia cells exposed to carcinogenic agents. Cancer Res. 42: 335-341.

Kimura, G., Katsumoto, T., and Itagaki, A. 1977. Morphological phenotype of temperaturesensitive mutants of simian virus 40 in productive infection. Virology 79: 355-368.

Kossakowska, A.E., Gallie, B.L., and Phillips, R.A. 1982. Fibroblasts from retinoblastoma patients: Enhanced growth in fetal calf serum and a normal response to ionizing radiation. J. Cell. Physiol. 111: 15-20.

McCormick, P.J, and Bertram, J.S. 1982. Differential cell cycle phase specificity for neoplastic transformation and mutation to ouabain resistance induced by $N$-methyl- $N^{\prime}$-nitro- $N$-nitrosoguanidine in synchronized C3H10T1/2 C18 cells. Proc. Natl. Acad. Sci. U.S.A. 79: 4342-4346.

Moshell, A.N., Scarpinato, R.G., Tarone, R.E., and Robbins, J.H. 1980. Cells from a patients with tuberous sclerosis are abnormally sensitive to ionizing radiation. Clin. Res. 28: 576 A [Abstr.].

Mulvihill, J.J. 1977. Genetic repository of human neoplasia. In Genetics of Human Cancer, Mulvihill, J.J., Miller, R.W., and Fraumeni, J.F., Ir., eds., Ravan Press, New York, pp. 137-143.

Ohno, K., Takeshita, K., and Arima, M. 1981. Frequency of tuberous sclerosis in San-in district (Japan) and birth weight of patients with tuberous sclerosis. Brain Dev. 3: 57-64.

Paterson, M.C., Sell, B.M., Smith, B.P., and Bech-Hansen, N.T. 1982. Impaired colony-forming ability following $\gamma$ irradiation of skin fibroblasts from tuberous sclerosis patients. Radiat. Res. 90: $260-270$.

Pfeffer, L., Lipkin, M., Stutman, O., and Kopelvich, L. 1976. Growth abnormalities of cultured human skin fibroblasts derived from individuals with hereditary adenomatosis of the colon and rectum. J. Cell. Physiol. 89: 29-38.

Roos, R.P., Kirkpatrick, C., Godoth, N., Berman, W., and Rary, J. 1977. An immunological and 
cytogenetic investigation of tuberous sclerosis. Ann. Neurol. 1: 192-194.

Scudiero, D.A. 1980. Decreased DNA repair synthesis and defective colony-forming ability of ataxia telangiectasia fibroblast cell strains treated with $N$-methyl- $N^{\prime}$-nitro- $N$-nitrosoguanidine. Cancer Res. 40: 984-990.

Scudiero, D.A., Meyer, S.A., Clatterbuck, B.E., Tarone, R.E., and Robbins, J.H. 1981. Hypersensitivity to $N$-methyl- $N^{\prime}$-nitro- $N$-nitrosoguanidine in fibroblasts from patients with Huntington disease, familial dysautonomia, and other primary neuronal degeneration. Proc. Natl. Acad. Sci. U.S.A. 78: 6451-6455.

Scudiero, D.A., Moshell, A.N., Scarpianto, R.G., Meyer, S.A., Clatterbuck, B.E., Tarone, R.E., and Robbins, J.H. 1982. Lymphoblastoid lines and skin fibroblasts from patients with tuberous sclerosis are abnormally sensitive to ionizing radiation and to a radiomimetic chemical. $J$. Invest. Dermatol. 78: 234-238.

Shiloh, Y., Tabor, E., and Becker, Y. 1982. Colony-forming ability of ataxia telangiectasia skin fibroblasts is an indicator of their early senescence and increased demand for growth factors. Exp. Cell Res. 140: 191-199.

Smith, P.J. and Paterson, M.C. 1980. Defective DNA repair and increased lethality in ataxia telangiectasia cells exposed to 4-nitroquinoline-1-oxide. Nature 287: 747-750.

Suzuki, Y. 1977. Cytogenetical study in tuberous sclerosis. Brain Nerve 29: 537-542 (in Japanese).

Takebe, H., Furuyama, J., Miki, Y., and Kondo, S. 1972. High sensitivity of xeroderma pigmentosum cells to the carcinogen 4-nitroquinoline-1-oxide. Mutat. Res. 15: 98-100.

Wade, M.H. and Chu, E.H.Y. 1979. Effects of DNA damaging agents on cultured fibroblasts derived from patients with Cockayne's syndrome. Mutat. Res. 59: 49-60.

Weichselbaum, R.R., Nove, J., and Little, J.B. 1978. X-ray sensitivity of diploid fibroblasts from patients with hereditary or sporadic retinoblastoma. Proc. Natl. Acad. Sci. U.S.A. 75: 39623964.

Weksberg, R., Buchwald, M., Sargent, P., Thompson, M.W., and Siminovitch, L. 1979. Specific cellular defects in patients with Fanconi anemia. J. Cell. Physiol. 101: 311-324.

Zelkowitz, M. 1981. Neurofibromatosis fibroblasts. Abnormal growth and binding to epidermal growth factor. In Advances in Neurology, Riccardi, V.M. and Mulvihill, J.J., eds., Vol. 29, Raven Press, New York, pp. 173-189. 